\title{
Uma Ferramenta para Apoiar Professores no Planejamento de Trabalhos em Grupo: Um Estudo de Caso
}

\author{
Edmar Welington Oliveira ${ }^{1}$, Marcos Roberto da Silva Borges $^{2}$ \\ Departamento de Ciência da Computação - Universidade Federal de Juiz de Fora \\ (UFJF) - Juiz de Fora, MG, Brasil \\ ${ }_{2}^{2}$ TECNUN - Universidade de Navarra, Donostia, San Sebastián, Espanha \\ oliveira.edmar@ufje.edu.br, mborges@tecnun.es
}

\begin{abstract}
This study proposed a computational tool to support educators in planning group learning scenarios. A case study was carried out with educators in real planning situations in their undergraduate courses. The results showed that, for the considered sample, the tool was able to support and guide the educators throughout the process, helping them both in specifying relevant elements to the process and in their understanding. The tool, therefore, shows potential to prevent group learning scenarios from being inappropriately and inefficiently structured, reducing the chances of an ineffective learning.
\end{abstract}

Resumo. Neste estudo, propõe-se uma ferramenta computacional para apoiar professores no planejamento de cenários de aprendizagem em grupo. Realizouse um estudo de caso, com professores em situações reais de planejamento em suas disciplinas de graduação presencial. Os resultados obtidos mostraram que, para a amostra considerada, a ferramenta foi capaz de apoiá-los e orientá-los ao longo do processo, ajudando-os tanto na especificação de elementos relevantes ao processo quanto na sua assimilação. A ferramenta, pois, apresenta potencial para evitar que cenários de aprendizagem em grupo sejam inapropriadamente e ineficientemente estruturados, diminuindo as chances de um aprendizado pouco efetivo.

\section{Introdução}

É crescente o interesse pelo emprego da aprendizagem colaborativa (AC) como estratégia para se prover cenários instrucionais capazes de oportunizar ao aluno o desenvolvimento de habilidades e conhecimentos. Entretanto, o simples fato de colocar alunos trabalhando juntos não garante uma aprendizagem efetiva [Isotani et al., 2013]. De fato, estudos que discorrem acerca do potencial dos cenários de AC enfatizam que a chance do aluno obter um aprendizado expressivo e duradouro diminui significativamente quando eles não são apropriadamente estruturados [Isotani et al., 2010]. De acordo com Dillenbourg (2002), o planejamento inadequado de cenários de $\mathrm{AC}$ é uma das principais razões de insucesso da aprendizagem em grupo.

Apesar de cenários de $\mathrm{AC}$ demandarem um planejamento cuidadoso, é evidente a complexidade envolvida - decorrente da necessidade do professor lidar com inúmeros requisitos e restrições, intrínsecos ao próprio processo. Sua estruturação deve não apenas considerar a necessidade de se orientar os alunos quanto à sua conduta, às atividades que devem executar e às interações com seus pares, mas também oportunizar aos professores realizar, em detalhes, o monitoramento, a análise e a avaliação do processo instrucional [Battou et al., 2016; Kaendler et al., 2015; Bennett et al., 2015]. Parte da dificuldade está 
em transformar essas ponderações em elementos (parâmetros e/ou ações) que estruturem o cenário. Esse é um processo particularmente desafiador para, apesar de não limitado a, docentes iniciantes - os quais, em geral, não possuem as competências ou a experiência necessária à sua adequada realização [Clement et al., 2016; Isotani et al., 2013]. De fato, vários docentes não se sentem preparados para o planejamento de cenários de AC [Ruys et al., 2011; Gilles e Boyle, 2010]. Chikh (2014) corrobora ao mencionar que muitos dos conceitos intrínsecos e fundamentais ao processo são desconhecidos pelos professores. Consequentemente, cenários de $\mathrm{AC}$ são, com frequência, inapropriadamente [Barkley et al., 2014] e ineficientemente estruturados [Höver e Mühlhäuser, 2014] - viabilizando um aprendizado pouco efetivo ou mesmo inócuo [Bennett et al., 2015].

Perante o exposto, o problema de pesquisa abordado no presente estudo refere-se ao planejamento inadequado de cenários de AC. Parte-se da premissa de que, de maneira geral, professores não realizam o planejamento desses cenários levando em consideração a especificação de elementos (objetivos, parâmetros/ações de monitoramento, avaliação, etc.) fundamentais ao processo. Essa premissa foi objeto de estudo em pesquisa anterior [Oliveira e Borges, 2019], onde constatamos sua ocorrência para uma amostra particular de docentes. Neste sentido, é notória a necessidade de se prover professores com suporte e orientação quando da proposição de cenários de AC. Portanto, foi objetivo do presente trabalho prover uma infraestrutura computacional apta a orientar/auxiliar professores no processo de planejamento - expondo-os a elementos considerados relevantes ao processo e apoiando-os na sua especificação.

O presente estudo foi realizado sob a metodologia de estudo de caso, de natureza qualitativa e explanatória. Contou-se com a participação de docentes, atuantes na área da computação, em situações reais de concepção de trabalhos em grupo ao ministrarem suas disciplinas no âmbito da graduação presencial. Portanto, dado seu caráter, a pesquisa foi norteada na hipótese de que a infraestrutura proposta provê a esses docentes orientação e suporte durante o processo de planejamento, auxiliando-os tanto na sua realização como na sua assimilação. No tocante às limitações desta pesquisa, sublinhamos a seleção (não probabilística) e o tamanho da amostra (doze docentes) definida para o estudo de caso, e seu escopo - limitado ao ensino superior presencial no âmbito da computação. Ademais, dado o protocolo de coleta dos dados delineado, as informações providas pelos docentes através das entrevistas podem conter fontes de viés, configurando possível limitação. Em virtude da natureza da metodologia adotada, os resultados e conclusões deste estudo não podem ser generalizados - o que também deve ser apontado como potencial limitação. Todavia, o estudo é passível de replicação.

As seções a seguir inicialmente discorrem acerca da metodologia considerada no presente estudo. A seção 3 apresenta os resultados obtidos e os discute. Por fim, na seção 4, são apresentadas as considerações finais.

\section{Metodologia}

Como relatado na seção anterior, a literatura é clara sobre a importância do planejamento para os processos instrucionais baseados na aprendizagem colaborativa. Igualmente clara é a responsabilidade dos docentes na sua realização e a sua complexidade. Considerando essas premissas, realizamos uma pesquisa anterior [Oliveira e Borges, 2019] pautada no estudo da AC sob a perspectiva da estruturação do ambiente que a oportuniza. Em suma, o objetivo foi investigar e obter informações sobre o processo de planejamento realizado por docentes quando da proposição de trabalhos em grupos. A pesquisa foi realizada sob 
a metodologia de estudo de caso - de caráter qualitativo e exploratório. Em uma primeira etapa, realizamos uma revisão da literatura visando investigar e identificar os parâmetros mais significativos ao processo de planejamento de cenários de AC. Na segunda etapa, com base nesse levantamento, estruturamos um conjunto de recomendações/diretrizes, a ser ponderado pelo docente (quando da realização do planejamento), de como especificar esses parâmetros - a intenção, portanto, está em orientar o professor durante a realização do processo.

$\mathrm{Na}$ etapa três, a partir dessas recomendações, criamos um arcabouço para análise de planejamento. Esse arcabouço possibilita verificar/avaliar se o planejamento efetuado por um professor (i) não segue, (ii) segue parcialmente ou (ii) segue integralmente cada uma das recomendações. O resultado da análise do planejamento através do arcabouço é uma pontuação que representa o nível de aderência do planejamento às recomendações, a saber: nulo (não aderente), insuficiente (pouco aderente), regular (aderência mediana), bom (aderência forte) e excelente (totalmente aderente). Na última etapa, realizamos um estudo de caso para, através do uso do arcabouço proposto, responder à seguinte questão de pesquisa: ao proporem trabalhos em grupo, qual o nível de aderência do planejamento realizado pelos docentes às recomendações. Como parte do processo, também buscamos responder quais recomendações são seguidas pelos professores e como, se seguidas, elas são ponderadas.

O estudo de caso foi aplicado sob o escopo do ensino superior presencial na área de computação. Foram entrevistados (por meio de entrevistas semiestruturadas, seguindo um roteiro de perguntas abertas) 25 professores de uma universidade federal, com média de 13 anos de experiência em docência no ensino superior. As limitações da pesquisa se assemelham àquelas mencionadas, na seção introdutória, para o presente estudo - no que tange à amostra, ao escopo e aos dados autorrelatados pelos participantes. O Quadro 1 , de maneira sucinta, apresenta os 12 parâmetros e suas respectivas recomendações definidas na pesquisa supracitada. Por sua vez, o Quadro 2 apresenta o resultado geral do estudo de caso - explicitando (i) a pontuação do docente para cada recomendação, (ii) a pontuação geral e (iii) o nível de aderência às recomendações. O Quadro está em ordem decrescente quanto ao item "iii".

As pontuações do Quadro 2 foram definidas a partir das respostas dos professores às perguntas das entrevistas. Para cada recomendação, os docentes recebiam a pontuação “0”, " 0.5 " ou " 1.0 ", a depender se sua forma de realizar o planejamento de trabalhos em grupo não a seguisse, seguisse parcialmente ou seguisse integralmente, respectivamente. Portanto, a pontuação total (soma das pontuações de cada recomendação) poderia variar entre 0 (mínimo) e 12 (máximo). Os resultados exibidos no Quadro 2 mostram que, dos 25 professores, 21 realizam um planejamento "insuficiente" - portanto, não seguindo ou seguindo somente parcialmente várias das recomendações. Esses resultados corroboram aquilo que é explicitado na literatura: professores, em geral, não realizam o planejamento de atividades colaborativas levando em consideração vários dos parâmetros essenciais ao processo. Os resultados também evidenciaram que muitos dos docentes não especificam vários desses parâmetros por desconhecê-los ou simplesmente por não saber como fazêlo de maneira adequada. Os resultados, portanto, corroboram a necessidade de se prover docentes com suporte e orientação ao longo do processo de planejamento de cenários de AC. 


\begin{tabular}{|c|l|l|}
\hline \multicolumn{2}{|c|}{ Parâmetro de Planejamento } & \multicolumn{1}{|c|}{ Recomendação } \\
\hline 1 & Objetivos de aprendizagem do trabalho & Especificação a nível das atividades \\
\hline 2 & Objetivos de aprendizagem do alunos & Especificação a nível dos alunos \\
\hline 3 & Formação de grupos & Participação ativa do professor no processo \\
\hline 4 & Especificação de atividades & Especificação com alto nível de granularidade \\
\hline 5 & Adequabilidade de atividades & Especificação de acordo com as características dos alunos \\
\hline 6 & Divisão de atividades & Participação ativa do professor no processo \\
\hline 7 & Colaboração & Intencionalmente fomentada pelo professor \\
\hline 8 & Monitoramento do desenvolvimento & Deve ocorrer a nível das atividades \\
\hline 9 & Monitoramento do aprendizado & Deve ocorrer a nível dos alunos \\
\hline 10 & Orientação das atividades & Participação ativa do professor no processo \\
\hline 11 & Material de suporte & Deve auxiliar o desenvolvimento das atividades \\
\hline 12 & Avaliação do aprendizado & Individual e ocorrer ao longo do desenvolvimento do trabalho \\
\hline
\end{tabular}

Quadro 1. Parâmetros e recomendações de planejamento

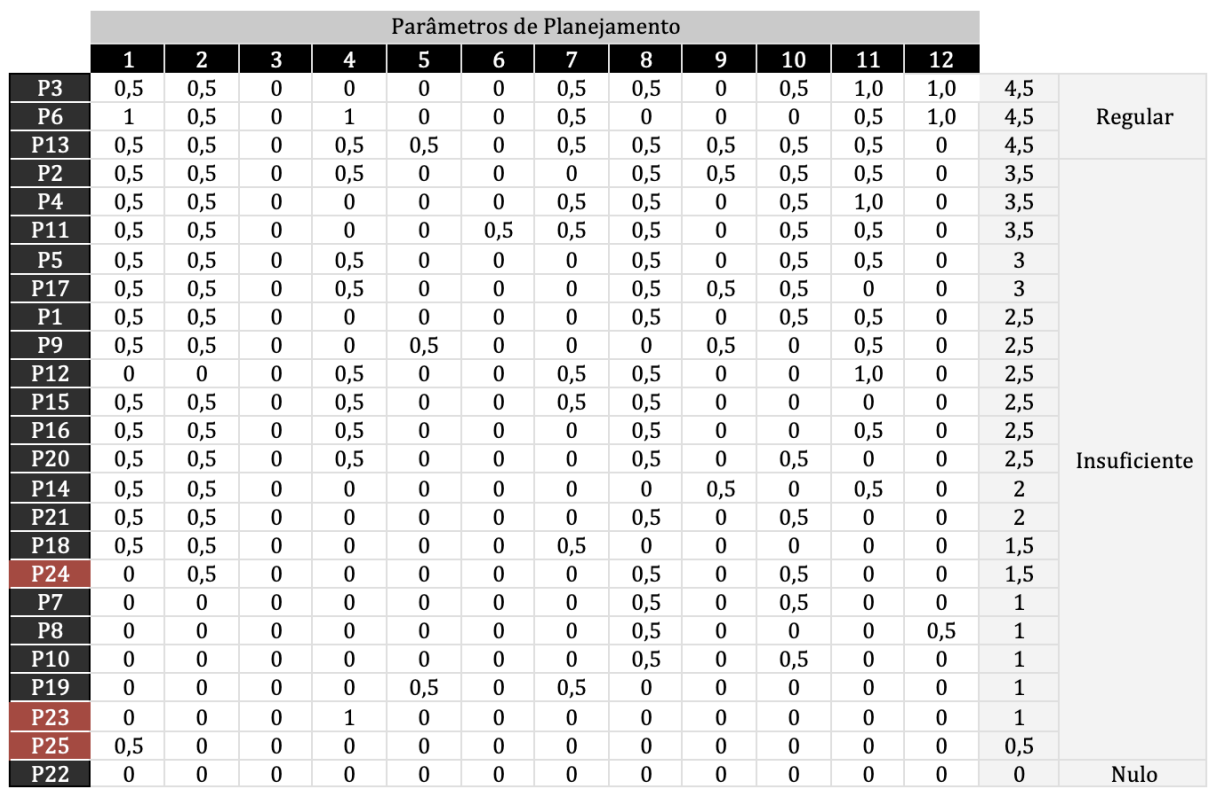

Quadro 2. Nível de aderências às recomendações de planejamento

Dos 25 docentes que participaram do estudo, 22 (P1 a P22), afirmaram fazer uso de trabalhos em grupo ao ministrar suas disciplinas de graduação; 3 (P23 a P25) disseram já terem adotado essa estratégia no passado, mas que não a usam mais (más experiências ao empregá-la e a dificuldade de planejamento dos trabalhos foram as justificativas mais mencionadas).

\subsection{Ferramenta de Planejamento}

Considerando os resultados obtidos em estudo prévio, sucintamente discutidos na seção anterior, desenvolvemos na presente pesquisa uma ferramenta computacional capaz de prover orientação e suporte aos professores quando do planejamento de cenários de AC. Em síntese, o propósito está em expor aos docentes, de maneira clara e sistematizada, os parâmetros/recomendações de planejamento, apoiando-os no seu entendimento e na sua especificação. É importante ressaltar que a ferramenta apenas orienta e apoia o professor na especificação desses parâmetros - não compelindo-o a especificá-los. A decisão final é sempre do professor.

Como parte do desenvolvimento da ferramenta, foram concebidos um arcabouço teórico e um processo de planejamento. $\mathrm{O}$ primeiro consiste em estrutura conceitual que conceitualiza o domínio de planejamento de cenários de AC - estruturada de acordo com as recomendações de planejamento definidas na pesquisa anterior. A estrutura especifica 
conceitos, relações e atributos inerentes ao domínio supracitado. O segundo consiste em um esquema que define as dependências entre os parâmetros de planejamento; portanto, explicitando a ordem em que eles devem ser especificados pelo professor. Embora seja opcional a especificação dos parâmetros pelo professor, é necessário que o processo siga uma sequência ordenada de etapas. Uma representação gráfica da estrutura é mostrada na Figura 1, com seus 14 conceitos e suas respectivas relações. Como definido, um Projeto é composto de Módulos (tópicos explorados em um trabalho) e Seções - nas quais Práticas (execuções de Atividades de Aprendizagem) são realizadas por Alunos. Práticas podem ser organizadas (sequenciadas e/ou relacionadas) através de Estruturas de Atividade. Os Alunos ou Grupos executam as práticas do Projeto. Os Alunos podem assumir Papeis no Projeto. Objetos de Aprendizagem podem ser usados para ajudar a realização de Práticas. Atividades de Monitoramento podem ser definidas para permitir ao professor monitorar Práticas ou Seções. Atividades de Avaliação podem ser definidas para avaliar Práticas ou Seções. Atividades de Suporte podem ser usadas pelo professor para auxiliar/orientar os Alunos no desenvolvimento de Práticas. Atividades de Contingência consistem em ações executadas em decorrência de alguma condição específica identificada pelo professor ao monitorar/avaliar Práticas ou Seções.

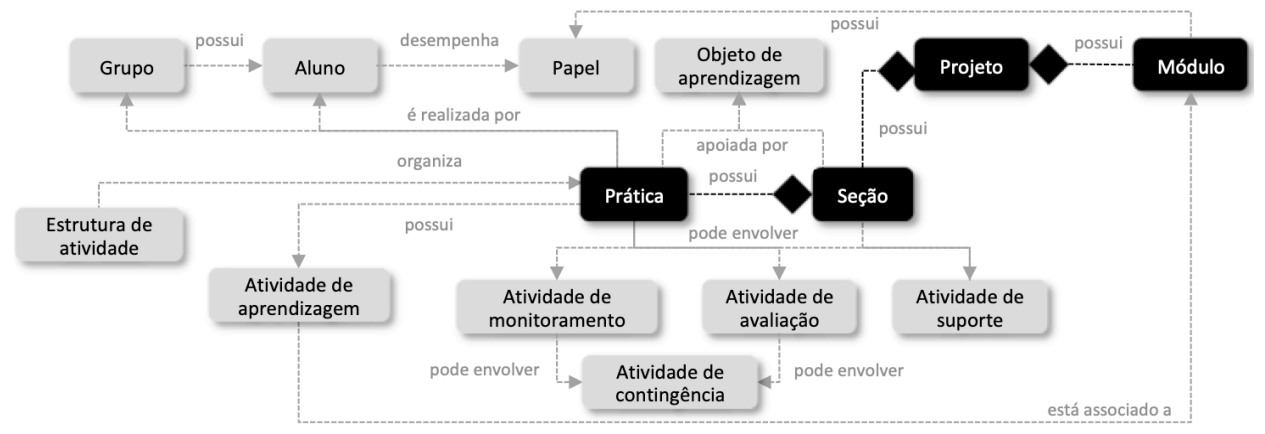

Figura 1. Estrutura conceitual de planejamento

Em relação à sua arquitetura, a ferramenta proposta foi implementada como uma aplicação Web monolítica, através de uma estrutura multicamada. Essa infraestrutura foi adotada por apresentar alto nível de abstração, flexibilidade e modularidade. Já o modelo de análise, projeto e programação adotado foi a Programação Orientada a Objetos. Uma lista de 86 funcionalidades foi implementada. Em síntese, tais funcionalidades permitem ao professor criar elementos em um projeto (p.ex.: criar atividade de aprendizagem, criar seções); editar (complementar ou modificar) elementos do projeto (p.ex.: editar atividade de avaliação); visualizar dados do projeto e seus elementos (p.ex.: visualizar atividade de monitoramento); relacionar elementos do projeto (p.ex.: incluir objeto de aprendizagem na seção); e excluir elementos do projeto (neste caso, eliminando uma relação entre dois ou mais elementos - p.ex.: excluir objeto de aprendizagem de prática - ou apagando um elemento definitivamente no projeto - p.ex.: excluir seção).

\subsection{Estudo de Caso}

Desenvolvida a ferramenta, fez-se necessário realizar sua avaliação. Buscou-se, portanto, analisar o processo de planejamento de cenários de AC por docentes em suas disciplinas de graduação presencial (especificamente, na área de computação) através do seu uso. $\mathrm{O}$ propósito da avaliação não é avaliar o planejamento - ou seja, se ele auxilia o docente na condução do processo de aprendizagem (quando de sua execução) ou mesmo se fomenta o aprendizado dos alunos. O que se propôs foi avaliar a percepção dos docentes quanto à 
orientação e suporte providos pela ferramenta e a aderência do planejamento estruturado por eles às recomendações de planejamento.

Conforme discorrido na seção de introdução, adotou-se a metodologia de estudo de caso, de caráter qualitativo e exploratório. Como hipótese, definiu-se que a ferramenta é capaz de orientar e auxiliar o docente na realização do planejamento, contribuindo não apenas para a obtenção de um planejamento mais aderente às recomendações, discutidas previamente, como também para o entendimento destas pelo professor. A realização do estudo ocorreu no transcorrer de um período letivo de uma universidade federal, com os professores em situações reais de elaboração de trabalhos em grupo em suas disciplinas. No tocante ao projeto, o estudo foi estruturado segundo a perspectiva de casos múltiplos, com múltiplas unidades de análise. A opção pelos casos múltiplos se mostrou adequada por, dado o cenário do estudo, haver diferentes tipos de condições de análise (discutidas nesta subseção); além disso, por possibilitar uma análise comparativa dos diversos casos - assim, propiciando uma visão ampla do fenômeno estudado. A opção pelas múltiplas unidades de análise decorre da necessidade de se analisar, para cada caso estabelecido, o fenômeno em estudo sob diferentes unidades/professores.

A definição dos casos e das unidades de análise foi fundamentada nos resultados obtidos na pesquisa prévia (Quadro 2). Para os casos, a definição considerou os seguintes critérios: uso da prática de trabalhos em grupo e o nível de aderência do planejamento às recomendações de planejamento. A partir desses critérios, foram definidos 4 casos para o estudo. O Caso 1 incluiu professores que já usaram a prática de trabalhos em grupo, mas que não a adotam mais. Os Casos 2, 3 e 4 incluíram docentes que fazem uso de trabalhos em grupo e cujos planejamentos são, respectivamente: pouco aderentes (pontuação entre 0 e 1,5), moderadamente aderentes (pontuação entre 2 e 2,5) e aderentes (pontuação entre 3 e 4,5) às recomendações de planejamento, quando comparados aos seus pares (Quadro 2). Os critérios para a definição das unidades de análise foram: disponibilidade/interesse do professor em participar do estudo e seu nível de aderência às recomendações (Quadro 2). Em específico, buscou-se selecionar para os Casos 2 e 4, respectivamente, os docentes com os menores e maiores níveis possíveis. Para o Caso 3, o interesse era ter indivíduos com níveis distintos. Foram selecionadas três unidades para cada caso. Esse quantitativo foi baseado em Yin (2015) - segundo o qual, em projetos de estudo de casos múltiplos, é necessário contar com ao menos duas unidades em cada caso. O Quadro 3 explicita todos os docentes selecionados - doutores, com média de 11 anos de experiência em docência no ensino superior.

\begin{tabular}{|c|c|c|c|c|c|c|c|c|c|c|c|}
\hline \multicolumn{3}{|c|}{ Caso 1 } & \multicolumn{3}{c|}{ Caso 2 } & \multicolumn{3}{c|}{ Caso 3 } & \multicolumn{3}{c|}{ Caso 4 } \\
\hline P23 & P24 & P25 & P18 & P19 & P22 & P14 & P16 & P20 & P2 & P6 & P17 \\
\hline 1 & 1,5 & 0,5 & 1,5 & 1 & 0 & 2 & 2,5 & 2,5 & 3,5 & 4,5 & 3 \\
\hline
\end{tabular}

Quadro 3. Definição das unidades de análise

Definidos os casos e suas unidades de análise, o protocolo de coleta de dados do estudo é como apresentado na Figura 2. Esse protocolo compreende três fases principais: preliminar, principal e final, com etapas distintas em cada uma. $\mathrm{Na}$ fase preliminar, com etapa única, foram definidos os casos e as unidades de análise - conforme anteriormente discorrido. A fase principal compreendeu as etapas de planejamento, análise e entrevista. Na primeira, os 12 professores participantes realizaram, através da ferramenta proposta, o planejamento de trabalhos em grupo. Para esta tarefa, iniciada simultaneamente com o início do período letivo, foi concedido um prazo de aproximadamente 1 mês. Na segunda 
etapa, os pesquisadores analisaram o planejamento implementado por cada professor, de modo a averiguar sua aderência às 12 recomendações de planejamento. Na última etapa, realizou-se uma entrevista com todos os docentes, visando analisar a percepção deles no tocante ao uso da ferramenta. Basicamente, buscou-se saber do professor se a ferramenta proposta o auxiliou e orientou na realização do planejamento, e também na compreensão dos parâmetros fundamentais ao processo - tanto no tocante à sua especificação quanto à relevância de se realizar um planejamento que os contemple. Para essas entrevistas, o esquema adotado foi o semiestruturado, com um roteiro de pesquisa abertas previamente definido.

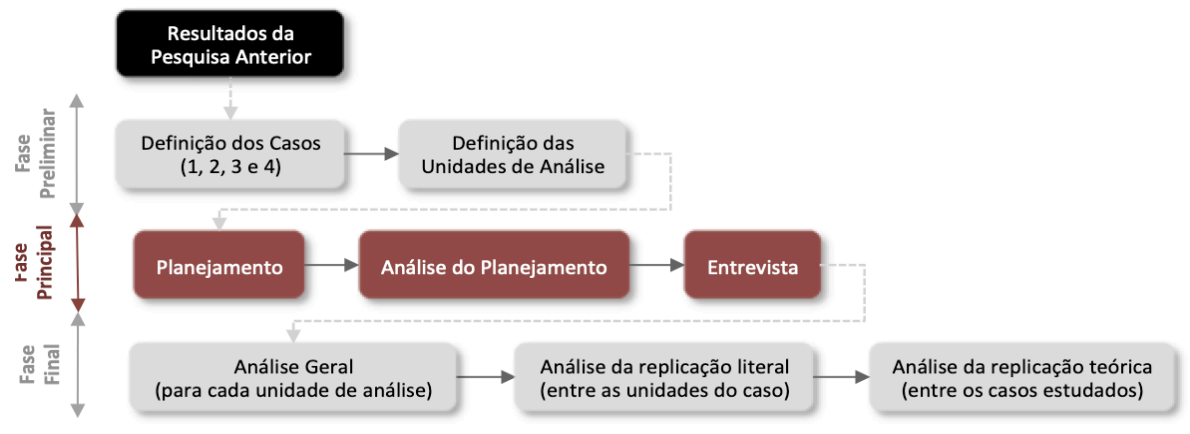

Figura 2. Protocolo do estudo de caso

A última fase compôs-se das seguintes etapas de análise: geral, replicação literal e replicação teórica. Na primeira, os pesquisadores realizaram, para cada professor, uma análise comparativa entre (i) o planejamento descrito no estudo exploratório realizado na pesquisa anterior e (ii) o realizado por meio da ferramenta proposta na presente pesquisa. Esse resultado serviu de base para, na segunda etapa, a análise de replicação literal (uma análise comparativa dos resultados das unidades de análise de cada caso) - explicitando, pois, as conclusões gerais para o caso estudado. As conclusões dessa análise forneceram as informações necessárias para a realização da análise de replicação teórica (uma análise comparativa entre os casos estudados).

\section{Resultados e Discussão}

O estudo de caso se propôs, como previamente discorrido, (i) avaliar a aderência do planejamento dos professores através do uso da ferramenta e (ii) a percepção deles no que tange à orientação e suporte providos pela mesma. Para a análise da aderência, foram empregados os mesmos critérios e procedimentos adotados na pesquisa anterior, com os professores recebendo, para cada uma das 12 recomendações, a pontuação " 0 ", " 0.5 " ou "1.0", a depender se seu planejamento não a seguisse, seguisse parcialmente ou seguisse integralmente. No Quadro 4 são apresentados os resultados da análise geral do estudo de caso. Para cada caso, e para cada professor, é explicitado a sua pontuação geral (ou seja, o nível de aderência de seu planejamento) obtida sem o uso da ferramenta (SF) e através de sua utilização $(\mathrm{CF})$. Pelos resultados, observa-se que todos os professores realizaram, através da ferramenta, um planejamento mais aderente às recomendações. Ao se analisar cada docente, individualmente, constata-se que a ferramenta foi, de fato, capaz de ajudálo durante o processo de planejamento. Por conseguinte, acerca da análise de replicação literal, todos os docentes de cada caso conseguiram realizar um planejamento com maior nível de aderência. O Quadro 5 apresenta os resultados (pontuações totais) de cada caso. 


\begin{tabular}{|c|c|c|c|c|c|c|c|c|c|c|c|c|}
\hline & \multicolumn{3}{|c|}{ Caso 1} & \multicolumn{3}{|c|}{ Caso 2} & \multicolumn{3}{|c|}{ Caso 3} & \multicolumn{3}{|c|}{ Caso 4} \\
\hline & P23 & P24 & P25 & P18 & P19 & P22 & P14 & P16 & P20 & P2 & P6 & P17 \\
\hline SF & 1 & 1,5 & 0,5 & 1,5 & 1 & 0 & 2 & 2,5 & 2,5 & 3,5 & 4,5 & 3 \\
\hline$\overline{\mathrm{CF}}$ & 5 & 8 & 4 & 8 & 5 & 5,5 & 5,5 & 7,5 & 6,5 & 7 & 6 & 6,5 \\
\hline
\end{tabular}

Quadro 4. Comparação individual dos resultados

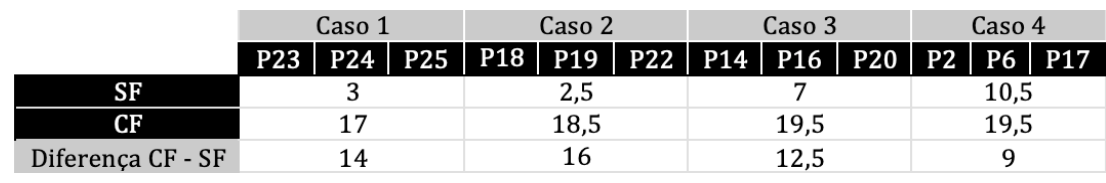

Quadro 5. Comparação dos resultados por caso

Em relação à análise de replicação teórica (comparação entre os casos), observase que, considerando os docentes que fazem uso da prática de trabalhos em grupo (casos 2, 3 e 4), a diferença de pontuação entre SF e CF é maior para o Caso 2 - com os casos 3 e 4 na sequência. Portanto, nos casos onde os docentes demonstraram dificuldades mais expressivas quanto à realização de um planejamento (sem uso da ferramenta) aderente às recomendações, a ferramenta apresentou maior capacidade de suporte. Em contrapartida, quanto menor foi essa dificuldade, menor também a capacidade de suporte provida. Esse parece ser um resultado natural, tendo em vista que os docentes com menos dificuldades em termos do planejamento são justamente aqueles que não apenas possuem uma melhor compreensão do processo e dos parâmetros fundamentais a ele, como também fazem uso (de muitos) desses parâmetros. Contudo, mesmo para estes professores, a ferramenta foi capaz de prover suporte, auxiliando-os na realização de um planejamento mais aderente. Ao se analisar as pontuações máximas CF, considerando todos os casos, nota-se que não houve uma diferença significativa entre elas. Esse resultado mostra que a ferramenta foi capaz de "uniformizar" o nível de aderência entre os casos (enquanto conjunto) e também entre os docentes (individualmente). Portanto, aqueles com dificuldade mais expressivas em realizar um planejamento mais aderente às recomendações (casos 1 e 2) conseguiram alcançar uma aderência (com uso da ferramenta) próxima ao apresentado pelos docentes dos casos 3 e 4.

A análise da percepção dos docentes quanto à orientação e suporte providos pela ferramenta baseou-se nas respostas obtidas da entrevista realizada na fase final do estudo de caso (Figura 2). Através dos questionamentos, buscou-se verificar, entre outros: (a) o quanto a ferramenta ajudou o docente a pensar o planejamento, (b) o quanto a ferramenta o ajudou e orientou na especificação dos parâmetros de planejamento, (c) se a ferramenta o fez refletir sobre a relevância desses parâmetros para o processo de planejamento e (d) se a ferramenta, de alguma forma, mudou a percepção do professor sobre como planejar trabalhos em grupo. Adicionalmente, para os docentes do Caso 1 - que não adotam mais práticas de trabalho em grupo -, foi perguntado (e) se a ferramenta os incentiva/encoraja a voltar a empregar esse tipo de prática.

Para o questionamento "a", todos enfatizaram a forte contribuição da ferramenta. Alguns afirmaram que nunca haviam pensado em realizar um planejamento ponderando sobre tantos parâmetros. Foi mencionado que alguns destes são cogitados, mas de forma intuitiva/abstrata e não formalmente especificado como é na ferramenta. Neste contexto, alegaram que a ferramenta os ajudou na concepção, na montagem, no processo de pensar o trabalho. Para a pergunta " $b$ ", todos mencionaram o significativo suporte provido pela ferramenta, enfatizando que tudo estava muito bem dividido, encadeado e explicado - do que poderia, e como deveria ser especificado. Alguns também enfatizaram o aprendizado 
proporcionado pela ferramenta, no sentido dela instigar pensar o trabalho de forma mais produtiva.

Para o questionamento "c", todos responderam positivamente, frisando que esses parâmetros são importantes tanto para o aluno, no seu processo de aprendizagem, quanto para os professores, que precisam acompanhar esse processo. Alguns disseram achar que realizavam um planejamento detalhado, mas que se surpreenderam por terem que pensar sobre elementos que eles não normalmente não pensam. Porém, outros comentaram não ter entendido muito bem certos parâmetros, ou não terem os considerado relevantes para aquilo que eles entendem como sendo um trabalho em grupo - mas salientaram que isso pode ser uma limitação deles próprios, de uma possível falta de conhecimento (ou visão) de que realmente significa trabalho em grupo. Já para a pergunta "d", todos responderam "sim". Eles relataram que passaram a ter outra visão de como planejar trabalhos, do que precisa ser pensado durante o processo - ainda que não venham a usar/especificar todos os parâmetros. Finalmente, para o questionamento "e" (apenas para professores do Caso 1), os três professores afirmaram que, em algum grau, a ferramenta suscita um estimulo para o uso da prática colaborativa. $\mathrm{O}$ fato da ferramenta prover todo suporte e orientação durante o processo é o grande atrativo - dado que diminui sensivelmente todo o trabalho envolvido. O fato dela também "forçar" o docente a pensar em vários aspetos do trabalho incentiva muito. Dois professores comentaram que, inevitavelmente, a ferramenta acaba um processo naturalmente mais trabalhoso e que isso poderia ser um possível ponto para desencorajamento.

A partir dos resultados do estudo de caso, tem-se que foi possível contribui para melhorar a aderência do planejamento dos docentes às recomendações de planejamento - resultado corroborado pelo fato de todos os 12 professores terem alcançado um maior nível de aderência ao usar a ferramenta proposta (quando comparado aos planejamentos implementados por eles sem o uso dela). Ademais, foi possível contribuir para melhorar o entendimento dos professores quanto às recomendações. Esse resultado é corroborado pelas respostas obtidas através da entrevista - a partir das quais, para praticamente todos os 12 professores: (i) as recomendações explicitadas pela ferramenta são relevantes para o processo de planejamento e (ii) a ferramenta os ajudou a compreender essa relevância. Portanto, para o estudo em questão e considerando a amostra adotada, é possível validar a hipótese de pesquisa. Pelos resultados, há indícios da necessidade de se prover suporte aos docentes tanto em termos da especificação de parâmetros de planejamento (cenários de AC) quanto na conscientização de sua relevância. É preciso, também, que esse suporte seja fundamentado em algum arcabouço teórico, que ocorra ao longo de todo o processo de planejamento e permita que o docente tenha liberdade de decisão, em termos de como realizar o planejamento.

\subsection{Abordagens Correlatas}

Diferentes abordagens voltadas à estruturação de práticas/cenários colaborativos são mencionadas na literatura; scripts colaborativos, padrões colaborativos e modelos de planejamento são algumas delas. Entretanto, todas possuem limitações quanto ao grau de suporte provido aos docentes e/ou à sua flexibilidade. No caso dos scripts colaborativos, uma das limitações consiste na falta de detalhamento/orientação quanto à maneira como professores devem especificar os parâmetros de planejamento. As propostas existentes se limitam a apresentar seus (específicos) parâmetros. No tocante aos padrões colaborativos, uma das limitações refere-se ao fato de terem propósitos específicos (p.ex.: organização 
de atividades, formação de grupos, etc.). Embora essa característica confira objetividade aos padrões, além de facilitar o entendimento das instruções neles contidas, a presumível necessidade de se combinar vários padrões - visando a estruturação dos muitos aspectos de um cenário colaborativo - impõe significativa complexidade e empenho aos docentes; além de demandar que tenham ciência de um amplo conjunto de padrões e conhecimento sobre seus respectivos fins. Outra limitação está no fato dos padrões compreenderem um conjunto pré-definido de instruções, não sendo possível ao docente modificá-lo para seu propósito particular. Quanto aos modelos de planejamento, a limitação está no fato deles proverem instruções demasiadamente abstratas/gerais, indicando as etapas que deveriam ser consideradas quando do planejamento, mas sem prover detalhes sobre como executar essas etapas (quais elementos devem ser considerados em cada uma ou como devem ser especificados).

Para além das abordagens anteriores, há também as ferramentas computacionais, direcionadas a auxiliar o processo de planejamento. Apesar da diversidade, toda possuem limitações. De fato, a maioria não provê qualquer orientação ao docente quanto à forma como o planejamento deve ser realizado, seja em relação aos processos envolvidos, seja no tocante aos elementos a serem especificados. Das que proveem algum suporte, todas o fazem de maneira limitada (p.ex.: algumas adotam padrões colaborativos - os quais já possuem suas próprias limitações -, limitando-se a alguns poucos; outras não empregam qualquer arcabouço teórico de apoio, deixando o processo de planejamento integralmente sob responsabilidade do professor e a mercê da sua própria experiência e conhecimento. Observa-se, portanto, que as ferramentas existentes também falham em prover suporte e flexibilidade aos docentes. Algumas dessas ferramentas são analisadas por Challco et al., (2016).

Diferentemente das abordagens mencionadas, a proposta discutida nesta pesquisa provê tanto flexibilidade quanto suporte e orientação ao professor. De fato, a ferramenta não apenas auxilia o docente na especificação dos vários elementos inerentes ao processo de planejamento (cobrindo diferentes aspectos da prática colaborativa), como também o auxilia na assimilação destes. O arcabouço teórico proposto é abrangente - e passível de evolução/expansão. Além disso, o professor possuiu liberdade para decidir como e quais parâmetros devem ser especificados - possibilitando-o, portanto, configurar um cenário de $\mathrm{AC}$ de acordo com suas necessidades e intenções.

\section{Considerações Finais}

Apesar do interesse no uso de cenários de aprendizagem colaborativa (AC) como estratégia para se promover o processo de aprendizagem, muitos professores acabam não realizando um planejamento adequado dos mesmos. Isso significa que muitos parâmetros relevantes não são ponderados e especificados - quer seja pela complexidade inerente ao processo, quer seja pela falta de experiência/conhecimento dos próprios docentes. Neste contexto, torna-se necessário prover docentes com suporte e orientação. Nesta pesquisa, portanto, foi proposta uma ferramenta computacional capaz de prover ambos. Um estudo de caso, com professores (da área da computação) em situações reais de planejamento de cenários de $\mathrm{AC}$ em suas disciplinas de graduação presencial, foi realizado. Os resultados mostram que a ferramenta não apenas auxiliou os docentes na análise e especificação de muitos desses parâmetros, como também contribuiu para a sua assimilação/compreensão pelos professores. Em termos de planejamento, é importante enfatizar que ele não é uma estratégia inconteste, no sentido de que o simples fato de ser realizado garantirá eficácia 
do processo de aprendizagem. Entende-se, na verdade, que um planejamento cuidadoso apenas aumenta as chances de um aprendizado efetivo ocorrer. Como trabalhos futuros, planeja-se uma reformulação da ferramenta proposta, uma extensão do arcabouço teórico que a suporta e uma replicação do estudo - envolvendo docentes de outras áreas e outras instituições.

\section{Referências}

Barkley, E. F., Major, C. H., K., Cross, K. P. (2014) "Collaborative Learning Techniques: A Handbook for College Faculty". 2nd ed. Jossey-Bass, San Francisco.

Battou, A., Baz, O., Mammass, D. (2016) "Learning design approaches for designing learning environments: a comparative study". International Conference on Multimedia Computing and Systems.

Bennett, S., Agostinho, S., Lockyer, L (2015) "Technology tools to support learning design: Implications derived from an investigation of university teachers' design practices". Computers \& Education, New York, v. 81, p. 211-220.

Challco, G. C., Bittencourt, I. I.; Isotani, S. (2016) Computer-based systems for automating instructional design of collaborative learning scenarios: a systematic literature review. International Journal of Knowledge and Learning, v. 11, n. 4.

Chikh, A. (2014) "A general model of learning design objects". Journal of King Saud University: Computer and Information Sciences, v. 26, n. 1, p. 29-40.

Clement, M., Vandeput, L., Osaer, T. (2016) "Blended learning design: a shared experience". Procedia: Social and Behavioral Sciences, v. 228, p. 582-586.

Dillenbourg, P. (2002) "Over-scripting CSCL: The risks of blending collaborative learning with instructional design". Three worlds of CSCL. Can we support CSCL? Heerlen: Open University Nederland, p. 61-91.

Gillies, R. M., Boyle, M. (2010) “Teachers' reflections on cooperative learning: issues of implementation”. Teaching and Teacher Education, New York, v. 26, p. 933-940.

Höver, K. M., Mühlhäuser, M. (2014) "Can We Use S-BPM for Modeling Collaboration Scripts?" Communications in Computer and Information Science, p. 174-187.

Isotani, S., Mizoguchi, R., Isotani, S., Capeli, O. M., Isotani, N., Albuquerque, A. R., Jaques, P. (2013) "A Semantic Web-based authoring tool to facilitate the planning of collaborative learning scenarios compliant with learning theories". Computer and Eucation, 63, p. 267-284.

Isotani, S., Mizoguchi, R., Inaba, A. (2010) "The foundations of a theory-aware authoring tool for CSCL design”. Computers and Education, 54(4), p. 809-834.

Kaendler, C. et al. (2015) "Teacher competencies for the implementation of collaborative learning in the classroom: a framework and research review". Educational Psychology Review, v. 54, n. 3, p. 505-536.

Oliveira, E. W., Borges, M. R. S. (2019) "How Educators Design Group Learning Scenarios in Higher Education?". International Conference on Information Technology Based Higher Education and Training, Magdeburg, Germany, p 1-9.

Ruys, I., Van Keer, H., Aeltermamn, A. (2011) "Student teachers' skills in the implementation of collaborative learning: a multilevel approach". Teaching and Teacher Education, New York, v. 27, p. 1090-1100.

Yin, R. K. (2015) "Estudo de caso: planejamento e métodos”. 5. ed. Porto Alegre: Bookman. 